- RAM, REV. ADM. MACKENZIE, V. 12, N. 2 - SÃO PAULO, SP • MAR./ABR. 2011 -ISSN 1678-6971 •

Submissão: 20 jul. 2010. Aceitação: 11 nov. 2010. Sistema de avaliação: às cegas dupla (double blind review). UNIVERSIDADE PRESBITERIANA MACKENZIE. Walter Bataglia (Ed.), p. 113-144.

\title{
AVALIAÇÃO DE INSOLVÊNCIA EM COOPERATIVAS DE CRÉDITO: UMA APLICAÇÃO DO SISTEMA PEARLS
}

\section{VALÉRIA GAMA FULLY BRESSAN}

Doutora em Economia Aplicada pelo Programa de Pós-Graduação em Economia Aplicada da Universidade Federal de Viçosa (UFV).

Professora da Faculdade de Ciências Econômicas da Universidade Federal de Minas Gerais (UFMG). Avenida Antônio Carlos, 6.627, sala 2.041, Pampulha, Belo Horizonte - MG - Brasil - CEP $31270-901$

E-mail: vfully@face.ufmg.br

\section{MARCELO JOSÉ BRAGA}

Doutor em Economia Rural pelo Centro de Ciências Agrárias da Universidade Federal de Viçosa (UFV).

Professor do Centro de Ciências Agrárias da Universidade Federal de Viçosa. Avenida P. H. Rolfs, s/n, Campus Universitário, Viçosa - MG - Brasil - CEP 36570-000

E-mail:mibraga@ufv.br

\section{AURELIANO ANGEL BRESSAN}

Doutor em Economia Aplicada pela Universidade Federal de Viçosa (UFV).

Professor da Faculdade de Ciências Econômicas da Universidade Federal de Minas Gerais (UFMG).

Avenida Antônio Carlos, 6.627, sala 4.039, Pampulha, Belo Horizonte - MG - Brasil - CEP $31270-901$

E-mail: bressan@face.ufmg.br

MOISÉS DE ANDRADE RESENDE FILHO

Doutor em Economia Aplicada pela Carlson School of Managment da University of Minnesota.

Professor da Faculdade de Economia, Administração, Contabilidade e Ciência da Informação da Universidade de Brasília (UnB).

Campus Universitário Darcy Ribeiro ICC, Norte, Asa Norte, Brasília - DF - Brasil - CEP 70919-970

E-mail: marf0013@gmail.com 


\section{RESUMO}

O presente estudo objetivou estimar as probabilidades de insolvência das cooperativas de crédito do Estado de Minas Gerais, condicionadas aos indicadores contábeis financeiros do sistema Pearls, o qual é recomendado pelo Conselho Mundial do Cooperativismo de Poupança e Crédito. Esse sistema tem como principal objetivo possibilitar o monitoramento do desempenho de cooperativas de crédito singulares, auxiliando os seus administradores a encontrar soluções para deficiências dessas instituições. No presente estudo, classificou-se como insolvente a cooperativa que deixou de enviar balanços para o Banco Central do Brasil, possuía patrimônio líquido negativo ou patrimônio líquido ajustado negativo, ou ainda que se encontrasse classificada nas seguintes situações com o Banco Central do Brasil: paralisada, em liquidação extrajudicial, cancelada/encerrada e em liquidação ordinária. A partir de uma base de dados de 9.456 observações coletadas de uma amostra de II2 cooperativas filiadas ao Sicoob-Crediminas, no período entre janeiro de 1995 e maio de 2008 , modelos da classe Logit foram estimados. Os resultados obtidos com o melhor ajuste permitem inferir que os indicadores "operações de crédito vencidas/carteira classificada total", "capital institucional/ ativo total", "ativos não direcionados com a atividade-fim da cooperativa/ativo total" e "rendas de prestação de serviços/despesas administrativas" foram os mais relevantes na determinação da probabilidade de insolvência das cooperativas na amostra. Tais resultados corroboram a hipótese de que o monitoramento de índices contábeis financeiros do sistema Pearls, os quais não têm sido o foco da análise tradicional de balanços, é importante para a determinação da probabilidade de insolvência de cooperativas de crédito, ao auxiliar seus administradores na identificação dos fatores de risco, bem como na criação de um referencial para comparação do desempenho das cooperativas, facilitando o processo de supervisão por parte dos órgãos reguladores. No entanto, a ampliação dos resultados aqui obtidos para períodos posteriores e outras cooperativas de crédito brasileiras deve ser feita com cuidado, de tal modo que especificações alternativas devem ser avaliadas para captar mudanças na conjuntura econômica 
e na estrutura administrativa das cooperativas, as quais podem influenciar nos indicadores contábeis e financeiros destas.

\section{PALAVRAS-CHAVE}

Insolvência; Indicadores contábeis financeiros; Cooperativas de crédito; Sistema Pearls; Logit.

\section{INTRODUÇÃO}

As demonstrações contábeis têm por objetivo apresentar informações que viabilizem a compreensão dos fatos ocorridos nas entidades e, assim, auxiliem a tomada de decisões dos agentes econômicos. De acordo com Hendriksen e Breda (I999, p. 97), "para que os dados contábeis sejam relevantes para a tomada de decisões por investidores, eles devem servir de insumo para os modelos de tomada de decisão". Nesse sentido, Watts e Zimmerman (I986) afirmam que os indicadores contábeis financeiros são importantes fontes de insumos para análises de insolvência e falência. Mário e Aquino (2004) partilham dessa mesma opinião ao defenderem que índices extraídos das demonstrações contábeis poderiam ser empregados na estimação da probabilidade de insolvência de empresas, auxiliando, dessa forma, em análises de insolvência e falência.

Muitas análises de insolvência e falência têm sido feitas no setor bancário, o que é de interesse público (ATAY, 2006; BLISS; KAUFMAN, 2006), uma vez que a falência de instituições bancárias pode gerar consequências mais nefastas para a economia do que a falência de empresas não pertencentes ao setor financeiro. Nesse tocante, nos últimos 30 anos, problemas de insolvência bancária têm sido recorrentes em diversas partes do mundo (Campbell, 2007), o que só reafirma a importância de realizar estudos a respeito dessa temática como fizeram Mayes (2004, 2005), Atay (2006), Bliss e Kaufman (2006), Campbell (2006), Lastra (2008) e Imai (2009).

A importância de questões ligadas à insolvência de instituições financeiras é reconhecida pelo Conselho Monetário Nacional (CMN), o que se comprova com a aprovação pelo CMN, em 26 de março de 2009 , da implementação de um programa para criar condições para que bancos de menor porte voltassem a poder emprestar. O CMN implementou tal programa em reação ao acirramento da crise imobiliário-financeira americana que estava levando ao crescente descasamento entre ativos e passivos dos bancos e, com isso, aumentando as chances de 
insolvência dessas instituições. De fato, o agravamento da crise americana levou muitos investidores a retirar os seus depósitos dos bancos pequenos, fazendo que muitos desses bancos passassem a não ter mais condições de continuar emprestando e, em alguns casos, fossem forçados a se desfazer de carteiras de crédito já constituídas (OTTA, 2009; MODÉ, 2009).

Note-se que, na estrutura do Sistema Financeiro Nacional, as cooperativas de crédito são classificadas como instituições financeiras captadoras de depósitos à vista e, por isso, são normatizadas pelo CMN e supervisionadas pelo Banco Central (Bacen). A demanda pelos serviços prestados pelas cooperativas de crédito vem aumentando significativamente, sobretudo pelo fato de estas oferecerem taxas de juros e custos de serviços sensivelmente mais baixos quando comparados aos praticados pelo sistema bancário convencional. Assim, estudos que envolvam a análise de insolvência e falência de cooperativas de crédito são importantes para fornecer subsídios a políticas e intervenções do Banco Central, além de auxiliarem os administradores na gestão das cooperativas de crédito, tornando menor o risco para os agentes econômicos que transacionam com elas e para a economia como um todo.

O presente estudo contribui com a literatura sobre a utilização de demonstrações contábeis em análises de insolvência de instituições financeiras, notadamente as cooperativas de crédito, ao aplicar um modelo estatístico baseado no sistema Pearls a uma amostra de cooperativas de crédito do Estado de Minas Gerais. Especificamente, as cooperativas da amostra utilizada são filiadas ao Sicoob-Crediminas, que é parte integrante do Sicoob-Brasil.

De acordo com dados apresentados por Soares e Melo Sobrinho (2007), o Sicoob-Brasil congrega $46,32 \%$ das cooperativas singulares ${ }^{\mathrm{I}}$ brasileiras e é o maior sistema dentre os demais existentes no Brasil (por exemplo, Sicredi, Unicred, Ancosol, Cooperativas Independentes e outros sistemas). Já o Sicoob-Crediminas $^{2}$ congregava II7 cooperativas singulares localizadas no Estado de Minas Gerais, entre janeiro de 1998 e maio de 2008 . Destas, 97 estavam em funcionamento em maio de 2008 , o que constitui, aproximadamente, $50 \%$ das cooperativas de crédito mineiras filiadas ao Sicoob-Brasil.

As cooperativas podem ser classificadas como: singulares ou cooperativas de $I^{\circ}$ grau, que são aquelas constituídas por pelo menos vinte pessoas físicas; e cooperativas centrais, federações de cooperativas ou cooperativas de $2^{\circ}$ grau, que são constituídas de pelo menos três cooperativas singulares.

2 As atribuições das cooperativas centrais de crédito, especificadas na Resolução n 3.32I de 2005 do Banco Central do Brasil, são: supervisionar o funcionamento das cooperativas filiadas com vistas ao cumprimento da legislação e regulamentação em vigor, promover a capacitação permanente dos membros das cooperativas filiadas e dos seus supervisores e auditores, realizar auditoria de demonstrações financeiras das filiadas e comunicar ao Banco Central do Brasil irregularidades e situações de exposição anormal a riscos detectadas. 
O presente artigo está estruturado da seguinte forma: a seção 2 apresenta o referencial teórico sobre insolvência e os indicadores contábeis financeiros que darão embasamento ao desenvolvimento do trabalho, com destaque para a descrição do sistema Pearls; a seção 3 apresenta o modelo analítico; a seção 4 descreve a amostra e a fonte dos dados; a seção 5 discute os resultados obtidos; e a seção 6 expõe as considerações finais e sugestões para trabalhos futuros.

\section{INSOLVÊNCIA}

Nos últimos anos, a insolvência e os processos de falência de instituições financeiras vêm preocupando não somente os seus acionistas, mas também governos, empresas e pessoas físicas que aplicam seus recursos financeiros nessas instituições. De acordo com Mora (I994 apud GIMENES, I998), não há metodologia única para a construção de modelos de avaliação de insolvência e tampouco consenso teórico sobre qual a melhor metodologia a ser utilizada. Assaf Neto (198I) enfatiza que, desde que a insolvência seja um processo real e identificável nos balanços, é perfeitamente possível desenvolver alguma técnica para descobrir seus sintomas e orientar as cooperativas com vistas a implementar ajustes de atuação e adequação.

Gimenes (1998) define estado de insolvência como a situação em que a empresa declara suspensão de pagamentos ou quebra por impossibilidade de honrar as suas dívidas com os credores. Já Matias e Siqueira (I996) consideram insolvência como a situação em que a instituição sofre liquidação ou intervenção do Banco Central. Segundo Tzirulnik (I997), a intervenção só poderá ser realizada se forem verificadas anormalidades nos negócios sociais da instituição financeira. Por exemplo, a lei prevê as seguintes anormalidades: má administração, infrações a dispositivos bancários e impontualidade e/ou presunção de insolvência. Janot (I999) considera que uma instituição financeira deve ser considerada insolvente quando seu patrimônio líquido se torna negativo ou quando é impossível para ela continuar as operações sem que isso implique incorrer perdas que a levarão a apresentar patrimônio líquido negativo. Esse mesmo autor destaca ainda que uma instituição financeira é considerada insolvente quando o seu supervisor responsável a coloca em evidência, no entanto ressalta que esse tipo de abordagem apresenta a desvantagem de depender de critérios subjetivos de julgamento. "Por outro lado, como a colocação de um banco em evidência precede sua liquidação, um modelo que preveja esta classificação provê um tempo maior para ações corretivas" (JANOT, I999, p. 3).

Casos extremos de liquidez insuficiente podem acarretar a insolvência de uma instituição financeira, uma vez que o risco de liquidez decorre da capaci- 
dade ou não de a instituição financeira promover reduções em seu passivo ou financiar acréscimos em seus ativos. Quando uma instituição financeira apresenta liquidez inadequada, perde a capacidade de obter recursos, seja por meio do aumento de seus exigíveis, seja pela pronta conversão de seus ativos a custos razoáveis, afetando, assim, a sua rentabilidade. Dessa forma, a finalidade da administração de liquidez é assegurar que a instituição financeira seja capaz de cumprir, integralmente, todos os seus compromissos contratuais. Os elementos fundamentais para a sólida administração de liquidez incluem um bom sistema de administração de informações, controle central da liquidez, análise das necessidades líquidas de financiamento sob cenários alternativos, diversificação das fontes de financiamento e plano de contingências.

Com relação às causas que podem contribuir para o estado de insolvência, há diversas abordagens na literatura econômica. Para Muñoz (200I), são as condições econômicas e as medidas políticas que exercem influência na situação de solvência ou insolvência. Com relação às instituições financeiras, esse mesmo autor destaca que a insolvência decorre de fatores como fraudes, imprudência administrativa, ocorrência de prejuízos consecutivos, além da influência de fatores macroeconômicos. Segundo Gimenes (I998), os fatores de origem externa à instituição financeira que a levam à falência são queda da demanda, recessão da economia, crises econômicas, políticas governamentais equivocadas e mudanças sociais radicais e significantes. Como exemplos de fatores de origem interna à empresa que levam à insolvência, Gimenes (I998) destaca a ineficácia da direção, as estratégias errôneas e inadequadas adotadas, a utilização de sistema produtivo ineficiente, endividamento excessivo e elevada morosidade.

O Quadro I apresenta um sumário dos indicadores contábeis financeiros significantes para a detecção de situação de insolvência e de falência de empresas em diferentes estudos.

\section{OUADRO I}

ESTUDOS QUE TRATARAM A QUESTÃO DE INSOLVÊNCIA

E FALÊNCIA, E OS INDICADORES SIGNIFICATIVOS PARA AVALIAR ESSES EVENTOS

\begin{tabular}{lll}
\hline AUTORES & $\begin{array}{l}\text { EVENTO } \\
\text { ESTUDADO }\end{array}$ & INDICADORES CONTÁBEIS FINANCEIROS SIGNIFICATIVOS \\
\hline $\begin{array}{l}\text { Patrick (1936 } \\
\begin{array}{l}\text { apud SILVA, } \\
\text { 1983) }\end{array}\end{array}$ & Falência & $\begin{array}{l}\text { • Patrimônio líquido/passivo } \\
\bullet \text { Lucro líquido/patrimônio líquido }\end{array}$
\end{tabular}


- RAM, REV. ADM. MACKENZIE, V. 12, N. $2 \bullet$

\section{QUADRO I (CONTINUACÃ̃O)}

ESTUDOS QUE TRATARAM A QUESTÃO DE INSOLVÊNCIA

E FALÊNCIA, E OS INDICADORES SIGNIFICATIVOS PARA AVALIAR ESSES EVENTOS

\begin{tabular}{|c|c|c|}
\hline AUTORES & $\begin{array}{l}\text { EVENTO } \\
\text { ESTUDADO }\end{array}$ & INDICADORES CONTÁBEIS FINANCEIROS SIGNIFICATIVOS \\
\hline $\begin{array}{l}\text { Beaver (1968 } \\
\text { apud SILVA, } \\
\text { 1988) }\end{array}$ & Falência & $\begin{array}{l}\text { - Geração de caixa/dívida total } \\
\text { - Lucro líquido/ativo total } \\
\text { - Exigível total/ativo total } \\
\text { - Capital de giro/ativo total } \\
\text { - Liquidez corrente } \\
\text { - Capital circulante líquido - estoques/desembolsos } \\
\text { operacionais previstos. }\end{array}$ \\
\hline $\begin{array}{l}\text { Altman } \\
\text { (1968) }\end{array}$ & Falência & $\begin{array}{l}\text { - Ativo corrente - passivo corrente/ativo total } \\
\text { - Lucros retidos/ativo total } \\
\text { - Lucros antes de juros e impostos/ativo total } \\
\text { - Valor de mercado do equity3/exigível total } \\
\text { - Vendas/ativo total }\end{array}$ \\
\hline $\begin{array}{l}\text { Matias (1978 } \\
\text { apud SILVA, } \\
\text { 1983) }\end{array}$ & Insolvência & $\begin{array}{l}\text { - Patrimônio líquido/ativo total } \\
\text { - Financiamento e empréstimos bancários/ativo circulante } \\
\text { - Fornecedores/ativo total } \\
\text { - Ativo circulante/passivo circulante } \\
\text { - Lucro operacional/lucro bruto } \\
\text { - Disponível/ativo total }\end{array}$ \\
\hline Kanitz (1978) & Insolvência & $\begin{array}{l}\text { - Lucro líquido/patrimônio líquido } \\
\text { - Ativo circulante + realizável em longo prazo/exigível total } \\
\text { - Ativo circulante - estoque/passivo circulante } \\
\text { - Ativo circulante/passivo circulante } \\
\text { - Exigível total/patrimônio líquido }\end{array}$ \\
\hline Beaver (1966) & Falência & $\begin{array}{l}\text { - Índices para fluxo de caixa (4) } \\
\text { - Índices para resultado líquido (4) } \\
\text { - Índices de dívida em relação ao ativo total (4) } \\
\text { - Índices relacionando ativos líquidos em relação ao total de } \\
\text { ativos (4) } \\
\text { - Índices relacionando ativos líquidos e dívidas de curto prazo (3) } \\
\text { - Índices de giro (11) }\end{array}$ \\
\hline
\end{tabular}


- RAM, REV. ADM. MACKENZIE, V. 12, N. $2 \bullet$

\section{QUADRO I (CONTINUAÇ̃̃o)}

ESTUDOS QUE TRATARAM A QUESTÃO DE INSOLVÊNCIA

E FALÊNCIA, E OS INDICADORES SIGNIFICATIVOS PARA AVALIAR ESSES EVENTOS

\begin{tabular}{|c|c|c|}
\hline AUTORES & $\begin{array}{l}\text { EVENTO } \\
\text { ESTUDADO }\end{array}$ & INDICADORES CONTÁBEIS FINANCEIROS SIGNIFICATIVOS \\
\hline $\begin{array}{l}\text { Altman } \\
\text { (1968) }\end{array}$ & Falência & $\begin{array}{l}\text { - Capital circulante líquido/ativo total } \\
\text { - Lucros acumulados/ativo total } \\
\text { - Lucros antes dos juros e impostos/ativo total } \\
\text { - Valor de mercado do PL/passivo exigível a valores contábeis } \\
\text { - Vendas/ativo total }\end{array}$ \\
\hline $\begin{array}{l}\text { Altman, } \\
\text { Haldeman e } \\
\text { Narayanan } \\
\text { (1977) }\end{array}$ & Falência & $\begin{array}{l}\text { - Retorno dos ativos (Ebit/ativo total) } \\
\text { - Estabilidade dos lucros (erro padrão da estimativa de Ebit/ } \\
\text { - } \text { ativo total) } \\
\text { - Serviço da dívida (log Ebit/juros totais pagos) } \\
\text { - Liquidez corrente } \\
\text { - Capitalização (preço ações ordinárias/PL a valor de mercado) } \\
\text { - Tamanho (log ativo total) }\end{array}$ \\
\hline $\begin{array}{l}\text { Ohlson } \\
\text { (1974) }\end{array}$ & Falência & $\begin{array}{l}\text { - Log ativo total/ PIB } \\
\text { - Passivo/ativo total } \\
\text { - Capital de giro/ativo total } \\
\text { - Passivo circulante/ativo circulante } \\
\text { - Lucro líquido/ativo total } \\
\text { - Geração bruta de caixa/passivo } \\
\text { - Dummy: } 1 \text { se ativo total excede o ativo, e zero, caso } \\
\text { - } \text { - Dumtrário } \\
\text { - Relações entre os lucros dos períodos mais recentes }\end{array}$ \\
\hline $\begin{array}{l}\text { Cole e } \\
\text { Gunther } \\
(1995)\end{array}$ & Falência & $\begin{array}{l}\text { - } \text { Capital = razão entre o capital próprio e as provisões para } \\
\text { - } \text { Inadimplência/ativo total } \\
\text { - Receita líquida/ativo líquido médio } \\
\text { - Investimentos assegurados/ativo total } \\
\text { - Certificado de depósito bancário superior a } \$ 100.000 \text { /ativo } \\
\text { total } \\
\text { - Empréstimos comerciais e industriais/ativo total } \\
\text { - Empréstimos para produção agrícola/ativo total }\end{array}$ \\
\hline
\end{tabular}


- RAM, REV. ADM. MACKENZIE, V. 12, N. $2 \bullet$

\section{QUADRO I (CONTINUAC̄̃O)}

ESTUDOS QUE TRATARAM A QUESTÃO DE INSOLVÊNCIA E FALÊNCIA, E OS INDICADORES SIGNIFICATIVOS PARA AVALIAR ESSES EVENTOS

\begin{tabular}{|c|c|c|}
\hline AUTORES & $\begin{array}{l}\text { EVENTO } \\
\text { ESTUDADO }\end{array}$ & INDICADORES CONTÁBEIS FINANCEIROS SIGNIFICATIVOS \\
\hline $\begin{array}{l}\text { Cole e } \\
\text { Gunther } \\
(1995)\end{array}$ & Falência & $\begin{array}{l}\text { - Empréstimos para construção/ativo total } \\
\text { - Empréstimos para consumidores/ativo total } \\
\text { - Empréstimos para membros internos da instituição/ativo total } \\
\text { - Despesas fixas/ativo total } \\
\text { - Tamanho do ativo } \\
\text { - Crescimento do emprego não agrícola } \\
\text { - Dummy com valor } 1 \text { para países "rurais" }\end{array}$ \\
\hline $\begin{array}{l}\text { Matias e } \\
\text { Siqueira } \\
(1996)\end{array}$ & Insolvência & $\begin{array}{l}\text { - Custo administrativo } \\
\text { - Comprometimento do patrimônio líquido com crédito em } \\
\text { liquidação } \\
\text { - Evolução da captação de recursos }\end{array}$ \\
\hline Rocha (1999) & Insolvência & - Margem líquida \\
\hline $\begin{array}{l}\text { Wheelock e } \\
\text { Wilson (1994) }\end{array}$ & Falência & $\begin{array}{l}\text { - Total do equity/ativo total } \\
\text { - Empréstimos comerciais e industriais/total dos empréstimos } \\
\text { - Bens de imóveis próprios/ativo total } \\
\text { - Inadimplência/total do ativo } \\
\text { - Liquidez }\end{array}$ \\
\hline $\begin{array}{l}\text { Martins } \\
(2003)\end{array}$ & $\begin{array}{l}\text { Insolvência } \\
\text { (concordata) }\end{array}$ & $\begin{array}{l}\text { - Empréstimos bancários/ativo circulante } \\
\text { - Retorno sobre o patrimônio líquido }\end{array}$ \\
\hline $\begin{array}{l}\text { Deyoung } \\
\text { (2003) }\end{array}$ & Falência & $\begin{array}{l}\text { - Proibição legal de novas aquisições, em anos } \\
\text { - Ln do ativo total } \\
\text { - Total dos empréstimos/ativo total } \\
\text { - Inadimplência/ativo total } \\
\text { - Lucro líquido/ativo total } \\
\text { - Equity/ativo total }\end{array}$ \\
\hline $\begin{array}{l}\text { Carlson } \\
(2004)\end{array}$ & Falência & $\begin{array}{l}\text { - Número de empresas no país } \\
\text { - Novos bancos } \\
\text { - Log ativo total } \\
\text { - Empréstimos/ativo total } \\
\text { - Redesconto/ativo total }\end{array}$ \\
\hline
\end{tabular}


- RAM, REV. ADM. MACKENZIE, V. 12, N. $2 \bullet$

\section{QUADRO I (CONCLUSÃO)}

ESTUDOS QUE TRATARAM A QUESTÃO DE INSOLVÊNCIA E FALÊNCIA, E OS INDICADORES SIGNIFICATIVOS PARA AVALIAR ESSES EVENTOS

\begin{tabular}{|c|c|c|}
\hline AUTORES & $\begin{array}{l}\text { EVENTO } \\
\text { ESTUDADO }\end{array}$ & INDICADORES CONTÁBEIS FINANCEIROS SIGNIFICATIVOS \\
\hline $\begin{array}{l}\text { Bressan, } \\
\text { Braga e Lima } \\
(2004)\end{array}$ & Insolvência & $\begin{array}{l}\text { - Capitalização: patrimônio líquido/passivo real } \\
\text { - Cobertura voluntária = disponibilidades/passivo real } \\
\text { - Crescimento da captação total }\end{array}$ \\
\hline $\begin{array}{l}\text { Brown e Dinç } \\
(2005)\end{array}$ & Falência & $\begin{array}{l}\text { - Total do equity }{ }^{4} / a t i v o \text { total } \\
\text { - Dummy - antes da eleição }\end{array}$ \\
\hline $\begin{array}{l}\text { Corrêa, Costa } \\
\text { e Matias } \\
\text { (2006) }\end{array}$ & Insolvência & $\begin{array}{l}\text { - Custo de pessoal } \\
\text { - Captação com moeda estrangeira } \\
\text { - Spread }\end{array}$ \\
\hline $\begin{array}{l}\text { Braga et al. } \\
\text { (2006) }\end{array}$ & Insolvência & $\begin{array}{l}\text { - Liquidez } \\
\text { - Despesas de pessoal } \\
\text { - Volume de crédito concedido em relação ao patrimônio } \\
\text { líquido }\end{array}$ \\
\hline Imai (2009) & Insolvência & $\begin{array}{l}\text { - Capital/ativo } \\
\text { - Retorno sobre os ativos } \\
\text { - Dummy para cooperativa de } \text { crédito }^{6}\end{array}$ \\
\hline $\begin{array}{l}\text { Bressan } \\
\text { (2009) }\end{array}$ & Insolvência & $\begin{array}{l}\text { - Proteção (4) } \\
\text { - Efetiva estrutura financeira (6) } \\
\text { - Qualidade dos ativos (4) } \\
\text { - Taxas de retornos e custos (13) } \\
\text { - Liquidez (3) } \\
\text { - Sinais de crescimento (9) }\end{array}$ \\
\hline
\end{tabular}

Fonte: Elaborado pelos autores com base nos trabalhos citados.

Como se pode notar pelo Quadro I, indicadores contábeis financeiros têm sido amplamente utilizados, tanto em nível internacional quanto nacional, em análises de insolvência e de falência de empresas, bancos e cooperativas.

\footnotetext{
4 Equity = participação patrimonial ou participação acionária.

5 A variável dummy “antes de eleição" recebeu valor um para ocorrência de falência dentro de um ano antes da eleição.

6 O autor adicionou dummies para discriminar bancos por tamanho, associações de crédito e cooperativas de crédito.
} 


\subsection{INDICADORES CONTÁBEIS FINANCEIROS UTILIZADOS PARA ANÁLISE DE INSOLVÊNCIA EM COOPERATIVAS DE CRÉDITO}

Inicialmente, é importante destacar que o presente estudo considera insolvente toda cooperativa que deixou de enviar balanços para o Banco Central do Brasil, possuía patrimônio líquido negativo ou patrimônio líquido ajustado negativo ou encontrava-se classificada nas seguintes situações no Banco Central do Brasil: paralisada, em liquidação extrajudicial, cancelada/encerrada e em liquidação ordinária.

Como não existem indicadores contábeis financeiros consensualmente indicados pela literatura (Quadro I) como capazes de explicar insolvência e falência, o presente estudo utiliza a recomendação do Conselho Mundial do Cooperativismo de Poupança e Crédito (World Council of Credit Unions - Woccu ) que propõe o uso do sistema Pearls em análises financeiras de cooperativas de crédito, o qual é amplamente utilizado por seus afiliados.

Segundo Richardson (2002), o grupo de indicadores contábeis financeiros utilizados pelo Woccu desde 1990 tem sido aplicado à avaliação das seguintes áreas-chave operacionais das cooperativas de crédito singulares:

- $\quad$ Protection (proteção);

- Effective financial structure (estrutura financeira efetiva);

- Assets quality (qualidade dos ativos);

- Rates of return and costs (taxas de retorno e custos);

- Liquidity (liquidez);

- $\quad$ Signs of growth (sinais de crescimento).

Note-se que a conjunção das iniciais das áreas-chave operacionais avaliadas forma o acrônimo Pearls ("pérolas" em português). O Pearls foi adaptado pelo Woccu diretamente do U. S. Camels ${ }^{8}$ para o ambiente das cooperativas de crédito. Para tanto, muitas modificações foram necessárias em razão das peculiaridades das cooperativas de crédito (VASCONCELOS, 2006).

O Woccu foi fundado em I97I e tem como funções básicas representar, desenvolver e promover o cooperativismo de crédito, especialmente no assessoramento técnico em projetos de fomento de desenvolvimentos em países afiliados, e propor modelos de legislação, normas, estatutos, regimentos, fiscalização interna e externa (PAGNUSSATT, 2004).

8 Camels representa um conjunto de indicadores de desempenho utilizado nos Estados Unidos para monitoramento das instituições financeiras. O acrônimo Camels (camelos) vem das iniciais de capital (capital). assets (ativos), management (gestão), earnings (rentabilidade), liquidity (liquidez) e sensitivity to price risks (sensibilidade). Para obter maiores detalhes, ver Pagnussatt (2004, p. I42). 
O principal objetivo do Pearls é propiciar o monitoramento da performance de cooperativas de crédito singulares, auxiliando os seus administradores a encontrar soluções para deficiências dessas instituições. Além disso, o sistema Pearls permite detectar quando uma cooperativa possuísse estrutura de capital fraca e identificar as causas do problema. Em essência, o Pearls é um "sistema de avisoprévio" capaz de gerar informações preciosas (VASCONCELOS, 2006). Ainda segundo esse mesmo autor, os outros objetivos do uso do Pearls são: eliminar os diversos critérios usados pelas cooperativas singulares para avaliar suas operações, possibilitar a comparação do desempenho das cooperativas sobre uma base nacional e facilitar o controle pelos órgãos de supervisão.

Os princípios e conceitos do Pearls são apresentados a seguir com base na tradução realizada por Vasconcelos (2006, p. I2-I7) do manual do Woccu (RICHARDSON, 2002).

\section{Protection (proteção):}

A adequada proteção de ativos é a doutrina básica do novo modelo de cooperativa de crédito. A proteção é medida: i) comparando a adequação da provisão para perdas com créditos contra o montante de créditos vencidos; e ii) comparando as provisões para perdas em investimentos com o valor total de investimentos não regulamentados. A proteção contra perdas com créditos é julgada adequada se a cooperativa de crédito tem provisões suficientes para cobrir Io०\% de todos os créditos vencidos há mais de I2 meses e 35\% de todos os créditos vencidos entre I e 12 meses. [...]

The World Council of Credit Unions Inc. promove o princípio de que a provisão para perdas de crédito é a primeira linha de defesa contra créditos em situação anormal. O sistema PEARLS avalia a adequação da proteção proporcionada pela cooperativa de crédito comparando a provisão para perdas de crédito com os créditos vencidos.

2. Effective financial structure (estrutura financeira efetiva):

A estrutura financeira da cooperativa de crédito é o mais importante fator na determinação do potencial de crescimento, capacidade de resultados e força financeira total.

O sistema PEARLS avalia ativos, exigibilidades e capital, e recomenda uma estrutura "ideal” para as cooperativas de crédito. 


\section{$[\ldots]$}

As cooperativas de crédito são encorajadas a maximizar ativos geradores de renda como uma forma de alcançar sobras suficientes. Já a carteira de crédito é o mais lucrativo ativo da cooperativa. The World Council of Credit Unions, Inc. recomenda manter $70-80 \%$ do total de ativos em carteira de crédito. Excesso de liquidez é desencorajado porque as margens sobre os investimentos líquidos (p. ex. contas de poupança) são significativamente menores que os ganhos obtidos na carteira de crédito. Ativos não-lucrativos são desencorajados porque uma vez adquiridos, são frequentemente de difícil realização. A única maneira efetiva de manter o equilíbrio ideal entre ativos geradores de não geradores de renda é incrementar o volume de ativos geradores de renda.

\section{$[\ldots]$}

Uma alta percentagem de depósitos de poupança indica que a cooperativa de crédito desenvolveu programas efetivos de marketing e está bem no caminho de alcançar independência financeira.

\section{Assets quality (qualidade dos ativos):}

Ativos não-produtivos ou não-lucrativos são aqueles que não geram renda. Um excesso de ativos não-lucrativos afeta as receitas das cooperativas de crédito de maneira negativa. Os seguintes indicadores são usados para identificar o impacto dos ativos não lucrativos: créditos em atraso; porcentagem de ativos nãolucrativos; financiamento de ativos não-lucrativos. [...]

De todos os indicadores do PEARLS, o índice de crédito em atraso é a medida mais importante de fraqueza institucional. [...] A meta ideal é manter o índice de atraso abaixo de $5 \%$ do total dos créditos a receber.

Um segundo indicador-chave é a porcentagem de ativos não-lucrativos detidos pela cooperativa de crédito. [...] A meta é limitar os ativos não-lucrativos a um máximo de $5 \%$ do total dos ativos da cooperativa.

$[\ldots]$

Tradicionalmente, as cooperativas de crédito usam o capital social para financiar a aquisição de ativos fixos. Sob o modelo do WOCCU, o objetivo é financiar I००\% de todos os ativos não-lucrativos com o capital institucional da cooperativa de crédito, ou com outros passivos que não tem custo financeiro explícito. 


\section{Rates of return and costs (taxas de retorno e custos):}

O sistema PEARLS segrega todos os componentes essenciais das rendas líquidas para auxiliar no gerenciamento dos rendimentos dos investimentos e na avaliação das despesas operacionais. Desta maneira, PEARLS demonstra seu valor como uma ferramenta de gerenciamento. Diferentemente de outros sistemas que calculam rendimentos em base de ativos médios, PEARLS calcula rendimentos em base de investimentos reais ótimos. [...]

Também permite que as cooperativas de crédito sejam classificadas segundo os melhores e piores rendimentos. Comparando a estrutura financeira com os rendimentos, é possível determinar quão eficazmente a cooperativa de crédito pode colocar seus recursos produtivos em investimentos que produzem rendimento mais elevado.

5. Liquidity (liquidez):

O gerenciamento da efetiva liquidez se torna uma habilidade muito importante quando a cooperativa de crédito troca sua estrutura financeira baseada em quotas de associados pela volatilidade dos depósitos de poupança. Em muitas ações seguindo o modelo tradicional, as quotas de capital são muito ilíquidas e a maioria dos créditos externos tem um longo período de retorno, então existe pouco incentivo para manter reservas de liquidez. A liquidez é tradicionalmente vista em termos de caixa disponível para emprestar - uma variável exclusivamente controlada pela cooperativa de crédito. Com a introdução de depósitos de poupança sacáveis, o conceito de liquidez é radicalmente mudado. Liquidez agora se refere ao caixa necessário para retiradas - uma variável que a cooperativa de crédito pode não mais controlar.

$[\ldots]$

O sistema PEARLS analisa a liquidez sob duas perspectivas

a) Total das Reservas de Liquidez.

Esse indicador avalia a porcentagem de depósitos de poupança investida como ativos líquidos em qualquer uma Associação Nacional ou um banco comercial. A meta "ideal" é manter um mínimo de I5\% após o pagamento de todas as obrigações de curto prazo (30 dias e inferiores).

b) Fundo Líquidos Inativos.

As reservas de liquidez são importantes mas elas também implicam custo de oportunidade perdido. Os fundos em contas correntes e de poupança simples geram retornos desprezíveis em comparação com outras alternativas de investimentos. Consequentemente, é importante manter reservas de liquidez para um mínimo. O objetivo "ideal" dessa relação do PEARLS é reduzir a porcentagem da liquidez inativa para o mais perto possível de zero. 
6. Signs of growth (sinais de crescimento):

O único caminho de sucesso para manter ativos valorizados é pelo crescimento forte e acelerado dos ativos, acompanhado por rentabilidade sustentada. O crescimento por si só é insuficiente. A vantagem do sistema PEARLS é que ele vincula crescimento à rentabilidade, bem como a outras áreas-chave, avaliandose a força do sistema como um todo. O crescimento é avaliado em quatro áreaschave: ativos totais; depósitos de poupança; quotas de capital e capital institucional.

Vasconcelos (2006) analisou os principais modelos de rating e de análise econômico-financeira empregados pelo sistema cooperativista de crédito, quais sejam: Pearls, Alerta Temprana, indicadores e sinalizadores desenvolvidos pelo analista João Batista Brito (Desuc/GTSPA); sistema de análise do Sicredi (SAS), sistema de classificação de risco do Unicred, monitoramento on-line da Cecremge e Programa de Análise Financeira e de Risco do Sicoob (Proaf). Como resultado da análise, Vasconcelos (2006) sugere que deve ser utilizado o sistema Pearls adotado pelo Woccu, com as devidas adaptações.

Seguindo a recomendação de Vasconcelos (2006) e tomando por base os trabalhos de Bressan (2002), Richardson (2002), Vasconcelos (2006) e Ribeiro (2008), foram criados 39 indicadores 9 contábeis financeiros dentro da classificação Pearls. Esses indicadores são descritos a seguir no grupo do sistema Pearls a que pertencem.

I. P - protection (proteção)

- PI = provisão para liquidação duvidosa sob operações de crédito/carteira classificada total;

- $\mathrm{P}_{2}=$ operações de crédito vencidas/carteira classificada total;

- $\mathrm{P}_{3}=$ operações de risco de nível $\mathrm{D}$ até H/classificação da carteira de créditos;

- $\mathrm{P}_{4}$ = operações de risco de Nível D até H (percentual de provisão estimado de nível $\mathrm{D}$ até $\mathrm{H} /$ patrimônio líquido ajustado).

2. E - effective financial structure (estrutura financeira efetiva)

- EI = operações de crédito líquidas/ativo total;

- E2 = investimentos financeiros/ativo total;

- E3 = capital social/ativo total;

- $\mathrm{E}_{4}$ = capital institucional/ativo total;

9 Os interessados nas contas Cosif que compõem os indicadores devem solicitá-las por e-mail aos autores. 
- $\mathrm{E}_{5}=$ renda de intermediação financeira/ativo total médio;

- E6 = ativo total/patrimônio líquido ajustado.

3. A - assets quality (qualidade dos ativos)

- $\mathrm{AI}=$ ativo permanente + ativos não direcionados com atividade-fim da cooperativa/ patrimônio líquido ajustado;

- A2 (imobilização) = ativo permanente/patrimônio líquido ajustado;

- $\mathrm{A}_{3}=$ ativos não direcionados com a atividade-fim da cooperativa/ativo total;

- A4 = depósitos totais/ativo total.

4. $\mathrm{R}$ - rates of return and costs (taxas de retorno e custos)

- RI = rendas de operações de crédito/operações de crédito médias;

- $\mathrm{R} 2$ = renda líquida de investimento financeiro/investimento financeiro médio;

- $\mathrm{R}_{3}=$ despesas de depósito a prazo/depósitos a prazo;

- $\mathrm{R}_{4}=$ despesas de obrigações por empréstimos e repasses/obrigações por empréstimos e repasses médias;

- $\mathrm{R}_{5}=$ margem bruta/ativo total médio;

- R6 = despesas operacionais/ativo total médio;

- R7 = sobras/ativo total médio;

- $\mathrm{R} 8$ = sobras/patrimônio líquido ajustado médio;

- $\mathrm{R} 9=$ resultado da intermediação financeira/receita operacional;

- Rio = sobras/receita operacional;

- RII = rendas de prestação de serviços/despesas administrativas;

- RI2 = despesas de gestão/despesas administrativas;

- Ri3 = despesas administrativas/ativo total médio.

5. $\quad$ L - liquidity (liquidez)

- LI = disponibilidades/depósitos à vista;

- L2 = ativos de curto prazo/depósitos totais;

- L3 = caixa livre/ativo total.

6. S - signs of growth (sinais de crescimento)

- SI (crescimento da receita operacional $)=($ receita operacional do mês corrente/receita operacional do mês anterior) - I;

- S2 (crescimento da captação total) $=$ (captação total do mês corrente/captação total do mês anterior) - I;

- S3 (crescimento das operações de crédito com nível de risco D-H) = (operações de crédito com nível de risco D-H do mês corrente/operações de crédito com nível de risco D-H do mês anterior) - I; 
- $\mathrm{S}_{4}$ (crescimento dos ativos não direcionados com atividade-fim da cooperativa - Andaf $)=($ Andaf do mês corrente/Andaf do mês anterior $)-\mathrm{I}$;

- S5 (crescimento da provisão sobre operações de crédito) = (provisão sobre operações de crédito do mês corrente/provisão sobre operações de crédito do mês anterior) - I;

- S6 (crescimento das despesas administrativas $)=($ despesas administrativas do mês corrente/despesas administrativas do mês anterior) - I;

- S7 (Crescimento do patrimônio líquido ajustado) = (PLA do mês corrente/PLA do mês anterior) - I;

- S8 (Crescimento do ativo total) $=($ AT do mês corrente/AT do mês anterior) - I;

- S9 (crescimento das operações de crédito) $=$ (operações de crédito do mês corrente/ operações de crédito do mês anterior) - I.

\section{O MOdelo logit}

No presente artigo, as probabilidades de insolvência das cooperativas de crédito brasileiras filiadas ao Sicoob-Crediminas são estimadas com a utilização de um modelo Logit com dados empilhados, tal que a variável dependente $Y$ do modelo recebe o valor I, se a cooperativa tiver sido classificada como insolvente e o, caso contrário. O modelo de resposta binária Logit segue a forma geral:

$$
\operatorname{prob}(Y=1 \mid x)=\frac{e^{x \beta}}{1+e^{x \beta}}
$$

em que $\operatorname{prob}(Y=\mathrm{I} \mid x)$ denota a probabilidade de a cooperativa se tornar insolvente, dado o vetor $x$ de dimensão I $\times K$ de variáveis dependentes. $O$ primeiro elemento de $x$ é um e $K$ é o número de variáveis explicativas (indicadores contábeis financeiros) no modelo mais um; $\beta$ é o vetor de dimensão $K \times$ I de parâmetros do modelo; e é a base do logaritmo natural ou neperiano; e a função do lado direito da igualdade é a função de distribuição de probabilidade acumulada logística, a qual associa valores no intervalo $(-\infty, \infty)$ a valores no intervalo entre zero e um.

Como apenas dois eventos são factíveis, a probabilidade de uma cooperativa não se tornar insolvente, ou seja, $Y=0$, é (I $-\operatorname{prob}(Y=\mathrm{I} \mid x)$ ), que, no modelo Logit, é obtida com base na equação (2).

$$
\operatorname{prob}(Y=0 \mid x)=\frac{1}{1+e^{x \beta}}
$$


em que $\operatorname{prob}(Y=$ 이 $x)$ denota a probabilidade condicionada em $x$ de que uma cooperativa de crédito não se torne insolvente.

Considerando uma amostra aleatória de $Y$ com $I * T$ observações em que $I$ é o número de cooperativas na amostra e $T$ é o número de períodos na amostra, a probabilidade conjunta de observar essa amostra é dada pela função verossimilhança $L($.). Admitindo que cada observação na amostra foi aleatória e independentemente obtida da mesma distribuição de probabilidade e com base nas equações (I) e (2), a função verossimilhança do modelo Logit é expressa segundo a equação (3).

$$
L(\beta \mid x)=\prod_{i=1}^{I^{*} T}\left(\frac{e^{x_{i} \beta}}{1+e^{x_{i} \beta}}\right)^{Y_{i}}\left(\frac{1}{1+e^{x_{j} \beta}}\right)^{1-Y_{i}}
$$

em que $\Pi$ é o operador produtório; e $x_{i}$, o vetor de dimensão $\mathrm{x} \times K$ de dados da i-ésima observação das variáveis explicativas.

A estimação do modelo Logit é realizada via maximização da função verossimilhança (3) ou, equivalentemente, pela maximização da função logaritmo da verossimilhança $\ln L($.) com respeito ao vetor de parâmetros $\beta$. Tal procedimento de maximização é realizado numericamente. Assim, o vetor $\beta$ que maximiza a função (3) ou, equivalentemente, que maximiza o $\ln L($.) constitui a estimativa de máxima verossimilhança do vetor de parâmetros do modelo.

Para o modelo Logit, a razão de probabilidade é calculada com base nas equações (I) e (2), como apresentado na equação (4).

$$
\frac{\operatorname{prob}(Y=1 \mid x)}{\operatorname{prob}(Y=0 \mid x)}=e^{x \beta}
$$

Aplicando o logaritmo natural dos dois lados de (4), obtém-se o logaritmo da razão de probabilidade dado na equação (5).

$$
\ln \frac{\operatorname{prob}(Y=1 \mid x)}{\operatorname{prob}(Y=0 \mid x)}=x \beta
$$

Observe por (5) que o logaritmo natural da razão de probabilidade no caso do modelo Logit é linear nos parâmetros do modelo.

No modelo Logit, o efeito marginal da variável dependente $x_{k}$ para $k=2, \ldots$, $K$ sobre a probabilidade de $Y_{i}=$ I é calculada como em (6). 


$$
\frac{\partial \operatorname{prob}\left(Y=1 \mid x_{i}\right)}{\partial x_{k}}=\frac{e^{-x_{i} \hat{\beta}}}{\left(1+e^{-x_{i} \hat{\beta}}\right)^{2}} \hat{\beta}_{k}
$$

em que $\hat{\beta}$ é a estimativa de máxima verossimilhança do vetor de parâmetros $\beta$; e $\hat{\beta}_{k}$, a estimativa de máxima verossimilhança do coeficiente associado à variável explicativa $x_{k}$.

Note que o efeito marginal da variável dependente $x_{k} \operatorname{com} k=2, \ldots, K$ sobre a probabilidade de $Y=\mathrm{I}$ deve ser calculado como a média do valor do efeito marginal obtido para cada observação $i$ (GREENE, 2003).

\subsection{SELEÇÃO DAS VARIÁVEIS EXPLICATIVAS DO MODELO LOGIT FINAL}

Com base nos trabalhos de Lane, Looney e Wansley (I986) e Bressan (2002), foram utilizados os passos descritos a seguir para selecionar das inicialmente 39 variáveis do sistema Pearls aquelas que deveriam estar na formulação do modelo Logit final.

- Passo I: Estimação de modelos com uma única variável.

Dado que as variáveis do sistema Pearls possuem identidade de acordo com o grupo a que pertencem, serão ajustados modelos com uma variável explicativa de cada vez. As variáveis explicativas que forem significativas a ı०\% serão separadas daquelas que não se mostrarem significativas individualmente.

- Passo 2: Estimação de modelos com mais de uma variável.

Como as variáveis de um mesmo grupo podem possuir correlação entre si, será incluída uma variável de cada grupo de cada vez, e apenas as que forem significativas a I०\% permanecerão no modelo. As variáveis não significativas serão separadas novamente.

- Passo 3: Inclusão de variáveis nos modelos estimados.

Será inserida, individualmente, cada uma das variáveis que foram excluídas nos passos I e 2, visando verificar se elas passarão a ser significativas em relação às demais variáveis. Então, aquelas que se tornarem significativas serão incluídas no modelo.

- Passo 4: Primeira seleção de prováveis modelos.

É selecionado o modelo que contemplar o maior número de variáveis explicativas significativas a 10\%. Com base nesse modelo, estrutura-se outro modelo 
excluindo o maior número de variáveis com sinal contrário ao esperado, permanecendo no modelo apenas as variáveis significativas a 10\%.

- Passo 5: Definição do modelo com melhor ajuste segundo os critérios de Akaike (AIC) e de informação bayesiano (BIC).

De acordo com Heij et al. (2004), quanto menores forem os valores do AIC e BIC, melhor será o ajuste do modelo. Contudo, Hayashi (2000, p. 397) defende que o BIC é uma medida de ajuste mais consistente do que o AIC. Verbeek (2004, p. 285) destaca que, quando os dois critérios diferem em relação à indicação do modelo com melhor ajuste, o critério BIC deve ser preferido porque tem a propriedade de selecionar o modelo mais confiável em grandes amostras, ou seja, quando o número de observações tende a infinito como é o caso no presente estudo. Já o critério de AIC tende a selecionar o modelo com o maior número de parâmetros.

Após a execução dos cinco passos em que se utilizaram os 39 indicadores contábeis financeiros da classificação Pearls anteriormente descritos, concluiuse, tanto pelo critério AIC quanto pelo critério BIC, que o modelo com melhor ajuste aos dados do Sicoob-Crediminas para a amostra utilizada segue a especificação em (7), dada por:

$\ln \left(\frac{\operatorname{prob}\left(Y=1 \mid x_{i}\right)}{\operatorname{prob}\left(Y=0 \mid x_{i}\right)}\right)=\begin{aligned} & \beta_{0}+\beta_{1} \mathrm{P} 2_{i}+\beta_{2} \mathrm{E} 1_{i}+\beta_{3} \mathrm{E} 4_{i}+\beta_{4} \mathrm{~A} 3_{i}+\beta_{5} \mathrm{~A} 4_{i}+\beta_{6} \mathrm{R} 1_{i}+\beta_{1} \mathrm{R}_{i}+ \\ & +\beta_{8} \mathrm{R} 8_{i}+\beta_{9} \mathrm{R} 10_{i}+\beta_{10} \mathrm{R} 11_{i}+\beta_{11} \mathrm{R} 12_{i}+\beta_{12} \mathrm{~L}_{i}+\beta_{13} \mathrm{~S} 9_{i}\end{aligned}$

em que P2 = operações de crédito vencidas/carteira classificada total; EI = operações de crédito líquidas/ativo total; $\mathrm{E}_{4}=$ capital institucional/ativo total; $\mathrm{A}_{3}$ $=$ ativos não direcionados com a atividade-fim da cooperativa/ativo total; $\mathrm{A}_{4}=$ depósitos totais/ativo total; RI = rendas de operações de crédito/operações de crédito médias; $\mathrm{R}_{5}=$ margem bruta/ativo total médio; $\mathrm{R} 8=$ sobras/patrimônio líquido ajustado médio; RIo = sobras/receita operacional; RII $=$ rendas de prestação de serviços/despesas administrativas; Rı2 = despesas de gestão/despesas administrativas; $\mathrm{LI}=$ disponibilidades/depósitos à vista; e S9 (crescimento das operações de crédito) $=$ (operações de crédito do mês corrente/operações de crédito do mês anterior) - I.

\section{AMOSTRA E FONTE DOS DADOS}

A amostra de dados inicialmente utilizada possuía i6.oro observações obtidas a partir de II7 cooperativas singulares, portanto todas as cooperativas filiadas 
ao Sicoob-Crediminas no período entre janeiro de 1995 e maio de 2008. Contudo, como faltavam dados para o indicador contábil financeiro P2 para cinco cooperativas em vários meses, a amostra efetivamente utilizada compreendeu apenas 9.456 observações obtidas de Iı2 cooperativas, correspondendo, portanto, a $96 \%$ das cooperativas filiadas ao Sicoob-Crediminas de janeiro de 1995 a maio de 2008. Dentre as II2 cooperativas na amostra final, i5 foram classificadas como insolventes, o que corresponde a I3\% da amostra final utilizada. Todos os dados foram obtidos com o Sicoob-Crediminas e são de caráter confidencial.

\section{RESUltados E discuss Ão}

Os resultados obtidos com a estimação do modelo (7) são apresentados na Tabela I.

\section{TABELA I}

ESTIMATIVA DO MODELO (7) DOS DETERMINANTES

DA INSOLVÊNCIA NAS COOPERATIVAS DE CRÉDITO

FILIADAS AO SICOOB-CREDIMINAS, NO PERÍODO DE JANEIRO DE 2000 A JUNHO DE 2008

\begin{tabular}{cccc}
\hline VARIÁVEIS EXPLICATIVAS & COEFICIENTE & RAZÃO DE PROBABILIDADES & EFEITO MARGINAL \\
\hline P2 & $\begin{array}{c}6,3312 \\
(0,4786) * *\end{array}$ & $\begin{array}{c}561,8406 \\
(268,9182) * * *\end{array}$ & $\begin{array}{c}0,0789 \\
(0,0082) * * *\end{array}$ \\
\hline E1 & 6,8949 & 987,2235 & 0,0859 \\
& $(0,5594) * * *$ & $(552,2085) * * *$ & $(0,00809) * * *$ \\
E4 & $-12,0641$ & 0,0000 & $-0,1503$ \\
A3 & $(0,7191) * * *$ & $(0,0000) * * *$ & $(0,0142) * * *$ \\
A4 & 16,7736 & $1,93 \mathrm{E}+07$ & 0,2090 \\
& $(1,2772) * * *$ & $(2,46 \mathrm{E}+07) * * *$ & $(0,0217) * * *$ \\
\hline R1 & 1,3530 & 3,8691 & 0,0169 \\
& $(0,4036) * * *$ & $(1,5615) * * *$ & $(0,0051) * * *$ \\
\hline
\end{tabular}


- RAM, REV. ADM. MACKENZIE, V. 12, N. $2 \bullet$

\section{TABELA I (CONTINUAÇÃO)}

ESTIMATIVA DO MODELO (7) DOS DETERMINANTES

DA INSOLVÊNCIA NAS COOPERATIVAS DE CRÉDITO FILIADAS AO SICOOB-CREDIMINAS, NO PERÍODO DE JANEIRO DE 2000 A JUNHO DE 2008

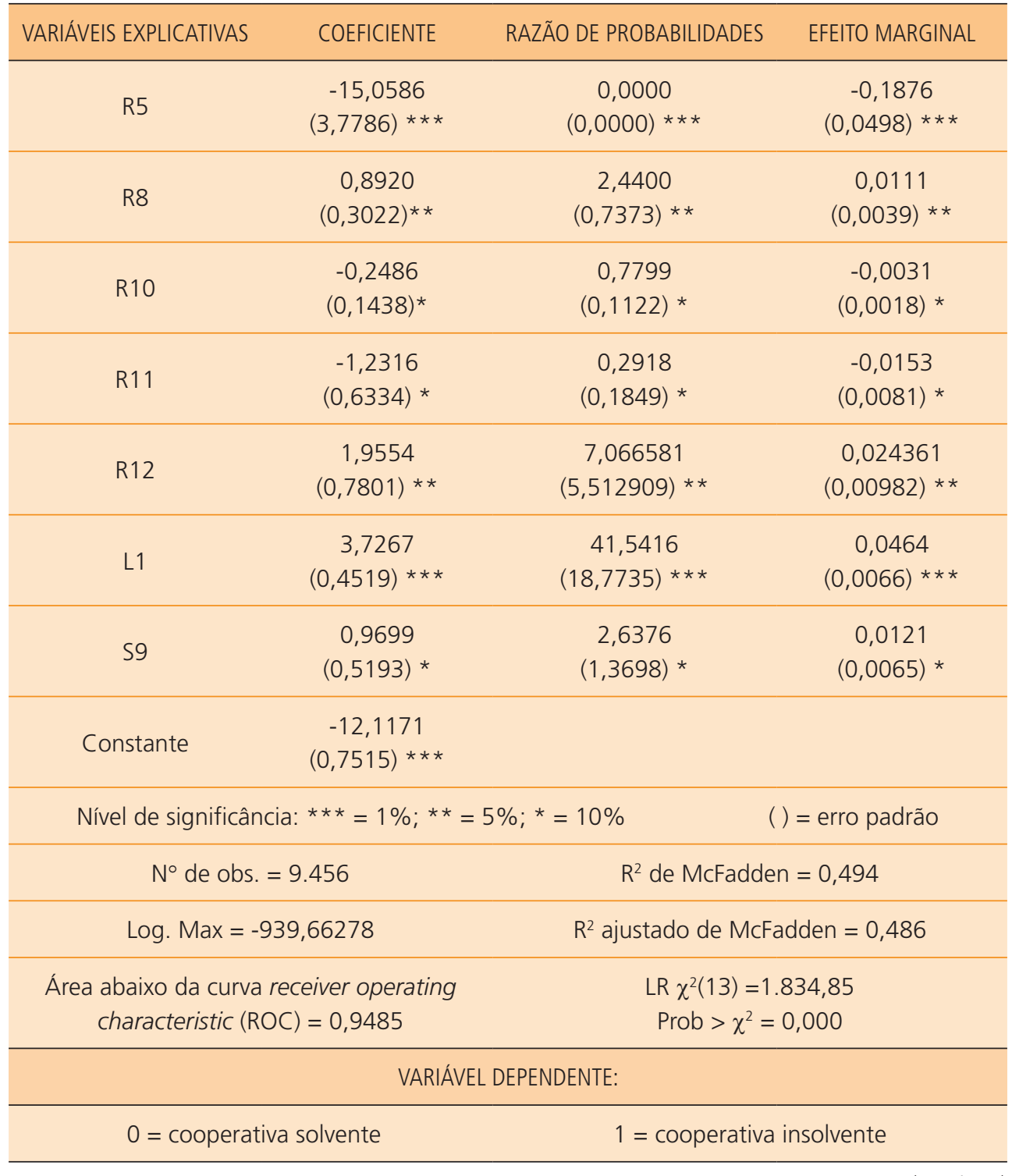




\section{TABELA I (CONCLUSÃO)}

\section{ESTIMATIVA DO MODELO (7) DOS DETERMINANTES \\ DA INSOLVÊNCIA NAS COOPERATIVAS DE CRÉDITO \\ FILIADAS AO SICOOB-CREDIMINAS, NO PERÍODO DE \\ JANEIRO DE 2000 A JUNHO DE 2008}

\section{VARIÁVEIS INDEPENDENTES:}

P2 = operações de crédito vencidas/carteira classificada total

E1 = operações de crédito líquidas/ativo total

E4 = capital institucional/ativo total

A3 = ativos não direcionados com a atividade-fim da cooperativa/ativo total

A4 = depósitos totais/ativo total

R1 = rendas de operações de crédito/operações de crédito médias

$\mathrm{R} 5$ = margem bruta/ativo total médio

R8 = sobras/patrimônio líquido ajustado médio

R10 = sobras/receita operacional

R11 = rendas de prestação de serviços/despesas administrativas

R12 = despesas de gestão/despesas administrativas

L1 = disponibilidades/depósitos à vista

S9 (crescimento das operações de crédito) $=$ (operações de crédito do mês corrente/operações de crédito do mês anterior) - 1

Fonte: Elaborada pelos autores com base nos resultados da pesquisa.

Nota-se, na Tabela I, que o modelo estimado é significante no nível de I\% de probabilidade pelo teste razão de verossimilhança (ver Tabela I em que LR $\chi^{2}$ (I3) $=\mathrm{I} .834,85 \mathrm{com}$ Prob $>\chi^{2}=0,000$ que é o p-valor do teste).

Pelos resultados na Tabela I, todos os I3 indicadores financeiros do sistema Pearls ou todas as I3 variáveis explicativas do modelo (7) foram estatisticamente significantes para explicar a probabilidade de insolvência das cooperativas filiadas ao Sicoob-Crediminas, pelo menos no nível de io\% de probabilidade. Note que, de acordo com a estatística descritiva e com o teste de Wilcoxon para diferenças entre as variáveis ${ }^{\mathrm{IO}}$, a maior parte das variáveis explicativas do modelo (7) apresentou diferenças entre o grupo de cooperativas solventes e insolventes, à exceção do índice R8.

Os indicadores apresentados a seguir destacaram-se como os mais relevantes para a análise de insolvência das cooperativas de crédito mineiras. Esses quatro indicadores mais relevantes foram selecionados com base nos resultados

ro As estatísticas descritivas e os resultados dos testes de Wilcoxon realizados para as variáveis do modelo podem ser solicitados por e-mail aos autores. 
apresentados na Tabela I e no fato de o estudo de Bressan (2009) também os ter destacado como estatisticamente significantes e relevantes para explicar a probabilidade de insolvência das 9II cooperativas de crédito filiadas ao Sicoob-Brasil analisadas em seu estudo.

- $\quad$ P2 $=$ operações de crédito vencidas/carteira classificada total: o índice P2 capta o efeito da inadimplência da cooperativa sobre a probabilidade de insolvência. O sinal positivo da estimativa do coeficiente $(6,33 \mathrm{I2})$ e do seu efeito marginal (ver Tabela I) indicam que quanto maior for a inadimplência, maior será a probabilidade de insolvência, o que está em consonância com a literatura. De fato, o efeito marginal de $\mathrm{P}_{2}$ informa que um aumento infinitesimal na razão operações de crédito vencidas sobre carteira classificada total gera um aumento de $7,89 \%$ na probabilidade de ocorrência de insolvência das cooperativas de crédito filiadas ao Sicoob-Crediminas.

- $\quad \mathrm{E}_{4}$ = capital institucional/ativo total: a variável E4 mede a porcentagem do ativo total financiado pelo capital institucional, que são as reservas legais e não distribuíveis, doações de capital e sobras não distribuídas. Assim, o capital institucional é constituído pelo capital da cooperativa, exceto o capital do cooperado. Como esperado, as estimativas para o coeficiente (-I2,064I) e o efeito marginal associado a essa variável demonstram que quanto maior a razão capital institucional sobre o ativo total, menor será a probabilidade de insolvência. Ou seja, um aumento infinitesimal do índice E4 gera uma redução de 15,03\% na probabilidade de ocorrência de insolvência das cooperativas de crédito filiadas ao Sicoob-Crediminas.

- $\quad \mathrm{A}_{3}$ = ativos não direcionados com a atividade-fim da cooperativa/ativo total: a variável $\mathrm{A}_{3}$ capta a relação entre os ativos que não geram receitas que são ativos não usuais em relação ao ativo total. O coeficiente estimado $(16,7736)$ e a probabilidade marginal $(0,2090)$ para esse indicador são ambos positivos, como esperado. Assim, uma variação infinitesimal no índice A3 causa um aumento de $20,9 \%$ na probabilidade de ocorrência de insolvência para as cooperativas de crédito filiadas ao Sicoob-Crediminas.

- $\quad$ RiI = rendas de prestação de serviços/despesas administrativas: o índice contábil financeiro RıI mede o percentual das despesas administrativas cobertas pelas rendas obtidas com a prestação de serviços pela cooperativa. Assim, quanto maior esse indicador, maior é a eficiência da cooperativa. O coeficiente estimado (-I,23IG) e a probabilidade marginal $(-0,0$ I53) são ambos negativos, como esperado. Uma variação infinitesimal no índice RII causa uma redução de I, $53 \%$ na probabilidade de ocorrência de insolvência das cooperativas de crédito filiadas ao Sicoob-Crediminas. 
Em suma, quanto maiores os índices $\mathrm{P}_{2}$ e $\mathrm{A}_{3}$, maior a probabilidade de insolvência das cooperativas de crédito filiadas ao Sicoob-Crediminas, e quanto maiores os indicadores E4 e RII, menor a probabilidade de insolvência das cooperativas filiadas ao Sicoob-Crediminas.

Com base no resultado do modelo Logit estimado apresentado na Tabela I, a probabilidade média de insolvência das cooperativas filiadas ao Sicoob-Crediminas foi calculada em $5 \%$. As probabilidades de insolvência estimadas com base no modelo Logit estimado estão no Gráfico I, em que é possível observar a alta concentração de resultados no intervalo de probabilidade de insolvência entre zero e $10 \%$.

\section{GRÁFICO I}

HISTOGRAMA COM A PROBABILIDADE ESTIMADA

DE INSOLVÊNCIA DAS COOPERATIVAS FILIADAS

AO SICOOB-CREDIMINAS

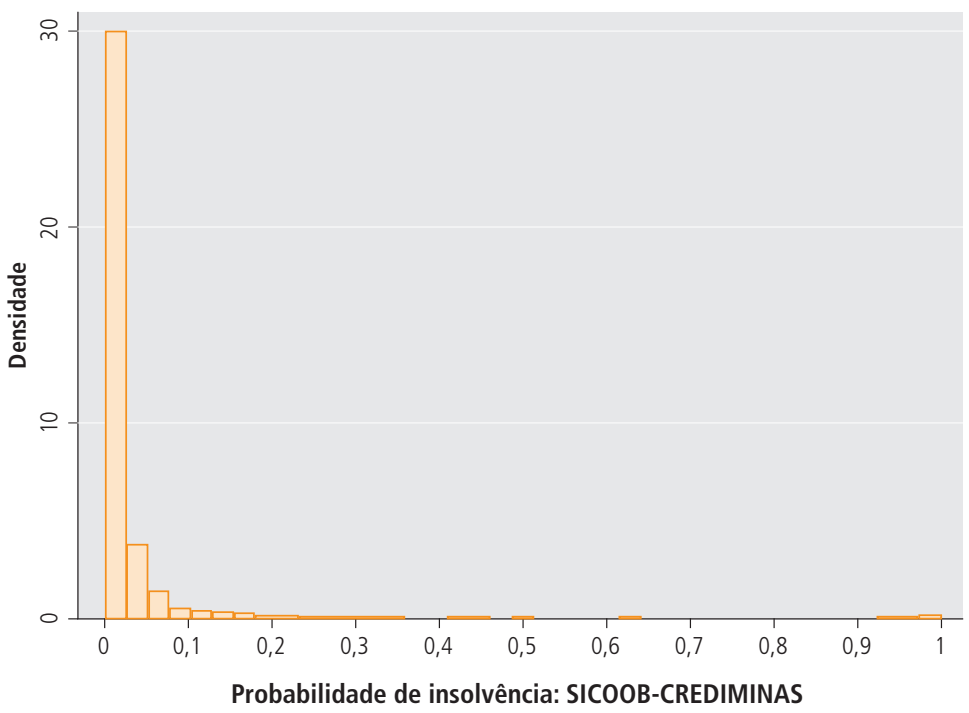

Fonte: Elaborado pelos autores com base nos resultados da pesquisa.

Apesar de não haver padrões definidos para avaliar a qualidade de ajuste de modelos binários, o percentual de predição correta do modelo estimado foi de 94,97\% (Tabela 2) para o Sicoob-Crediminas. Considerando o ponto de corte de $0,13^{\text {II }}$, o modelo estimado apresentou um nível de acerto de $72,32 \%$ para o 
grupo de cooperativas insolventes e de 96 ,I4\% para o grupo de cooperativas solventes (Tabela 2). Dessa forma, o modelo apresentou bom ajuste em termos de predição, o que é confirmado pela análise da área abaixo da curva ROC ${ }^{\mathrm{I2}}$ (Tabela I), que, apresentando o valor 0,9485 , sinaliza um bom poder preditivo do modelo estimado.

TABELA 2

CLASSIFICAÇÃO DO MODELO LOGIT PARA AS COOPERATIVAS FILIADAS AO SICOOB-CREDIMINAS, CONSIDERANDO O PONTO DE CORTE DE O,I3

\begin{tabular}{|c|c|c|c|}
\hline \multirow{2}{*}{ SITUAÇÃO DA COOPERATIVA } & \multicolumn{2}{|c|}{$\begin{array}{c}\text { CLASSIFICAÇÃO DA COOPERATIVA } \\
\text { PELO MODELO }\end{array}$} & \multirow{2}{*}{$\begin{array}{c}\text { PERCENTUAL PARCIAL DE } \\
\text { CLASSIFICAÇÃO CORRETA } \\
\text { DO MODELO }\end{array}$} \\
\hline & INSOLVENTE & SOLVENTE & \\
\hline Insolvente & 337 & 129 & $337 / 466=72,32 \%$ \\
\hline Solvente & 347 & 8.643 & $8.643 / 8.990=96,14 \%$ \\
\hline \multicolumn{3}{|c|}{ Percentual total de classificação correta do modelo } & $(337+8.643) / 9.456=94,97 \%$ \\
\hline
\end{tabular}

Fonte: Elaborada pelos autores com base nos resultados da pesquisa.

Por fim, uma das mais importantes implicações do presente estudo é a de que, apesar de as cooperativas de crédito filiadas ao Sicoob-Crediminas se encontrarem, em sua grande maioria, em situação de solvência, é recomendável que seus gestores monitorem constantemente os indicadores contábeis financeiros (P2, E4, E3 e RII) das cooperativas. Procedendo dessa maneira, os gestores terão uma boa ideia sobre a probabilidade de insolvência ou risco de insolvência da cooperativa gerenciada.

\section{CONSIDERAÇÕES FINAIS}

A aplicabilidade do sistema Pearls à análise de insolvência das cooperativas de crédito do Estado de Minas Gerais apresenta características interessantes aos usuários de informações contábeis financeiras destas instituições. Por exemplo,

I2 A curva receiver operating characteristic (ROC)) relaciona a sensibilidade versus a especificidade do modelo estimado. Um modelo com nenhum poder preditivo teria a curva ROC como uma linha de 45 graus. Quanto maior o poder preditivo do modelo, maior a curva, e a área sob a curva é utilizada como uma medida de capacidade preditiva do modelo. Para maiores detalhes sobre a curva ROC, consulte Statacorp (2007). 
com base nos resultados obtidos na presente pesquisa, foi possível demonstrar que os indicadores contábeis financeiros do sistema Pearls são relevantes para a avaliação de insolvência das cooperativas de crédito do Estado. Tal resultado corrobora as afirmações de Watts e Zimmerman (I986) e Mário e Aquino (2004) no que diz respeito ao fato de a contabilidade cumprir como função principal de "acumular e comunicar informações essenciais à compreensão das atividades de um empreendimento" (AMERICAN ACCOUTING ASSOCIATION, I957, p. I). Além disso, observou-se que o tratamento das informações contábeis utilizando o sistema Pearls gera um conjunto de informações significativas do ponto de vista estatístico. Com base nessa constatação, pode-se afirmar que as demonstrações contábeis apresentaram informações capazes de propiciar melhor compreensão da situação financeira das cooperativas de crédito mineiras. Essas informações estão ligadas a indicadores que relacionam variáveis, como operações de crédito vencidas, capital institucional, ativos não direcionados com a atividade-fim da cooperativa e receitas de prestação de serviços, com agregados contábeis tradicionais na análise financeira, como carteira classificada total, ativo total e despesas administrativas.

No entanto, é importante ressaltar que o modelo Logit utilizado no presente artigo apresenta limitações decorrentes do fato de empregar dados passados. Dessa forma, quando a conjuntura político-econômica e a estrutura administrativa das cooperativas se alteram, ou quando há períodos de recessão econômica e problemas relativos à probidade administrativa, entre outros fatores, é possível que ocorram alterações nos indicadores contábeis e financeiros capazes de explicar a insolvência das cooperativas mineiras. Em tais circunstâncias, o modelo deverá ser reespecificado e estimado com dados atualizados, de modo que as novas estimativas dos parâmetros do modelo Logit captem tais modificações.

Como sugestão para estudos futuros, tem-se a questão da avaliação da aplicabilidade de modelos de previsão de insolvência, para um ou dois passos à frente ${ }^{\mathrm{r} 3}$, para uma amostra de cooperativas de crédito brasileiras utilizando o sistema Pearls. Esse esforço de pesquisa teria como intuito comparar o desempenho preditivo do modelo Logit ante modelos tradicionais de insolvência, visando contribuir para o gerenciamento do risco de insolvência de instituições baseado em indicadores contábeis financeiros.

13 Previsão de insolvência um ou dois passos à frente é uma expressão utilizada em estudos dessa natureza que indica prever a insolvência para 6 meses e I2 meses à frente, ou para I2 meses e 24 meses à frente, ou quaisquer outros dois períodos posteriores à realização do estudo. 


\section{INSOLVENCY EVALUATION IN CREDIT UNIONS: AN APPLICATION OF THE PEARLS SYSTEM}

\section{ABSTRACT}

This study aimed at estimating the insolvency probability for Credit Unions from the State of Minas Gerais, conditioned on the Pearls system financial ratios which is recommended by the World Council of Credit Unions, a system whose main objective is to enable performance monitoring of individual credit cooperatives, helping their managers to find solutions to deficiencies of these institutions. In this study, insolvency was classified as the cooperative wich: failed to send statements to the Central Bank of Brazil, had negative equity or negative adjusted net worth, or even if it were classified in the following situations by the Central Bank of Brazil: paralyzed, in liquidation, canceled/closed and in ordinary liquidation. From a database of 9,456 observations collected from a sample of II2 cooperatives affiliated to Sicoob-Crediminas between January I995 and May 2008 , a set of Logit class models were estimated. The results obtained with the best fit allow us to infer that the financial ratios "Allowance for Loan Losses/ Allowances Required for Overdue Loans", "Non-Financial Investments/Total Assets", "Non-Earning Assets/Total Assets", and "Services Income/ Managerial Expenses" were the most relevant in determining the likelihood of insolvency of cooperatives in our sample. These results support the hypothesis that the monitoring of financial accounting ratios of the Pearls system, which has not been the focus of the traditional analysis of balance sheets, is important for determining the probability of insolvency of credit unions, assisting their managers in identifying risk factors, as well as in creating a benchmark for comparing the performance of cooperatives, facilitating the supervision process by regulators. However, expansion of the estimated results for subsequent periods and other credit unions in Brazil must be done carefully, with alternative specifications to be evaluated in order to capture changes in the economic and administrative structure of the cooperatives, which may influence their accounting and financial indicators.

\section{KEYWORDS}

Insolvency; Accounting ratios; Credit unions; Pearls system; Logit. 


\section{EVALUACIÓN DE LA INSOLVENCIA EN LAS COOPERATIVAS DE CRÉDITO: UNA APLICACIÓN DEL SISTEMA PEARLS}

\section{RESUMEN}

Este estudio tuvo como objetivo estimar la probabilidad de insolvencia de las cooperativas de crédito del Estado de Minas Gerais, utilizando los indicadores financieros del sistema Pearls, el cual es recomendado por el Consejo Mundial de Cooperativas de Ahorro y Crédito, e tiene como principal objetivo permitir la supervisión del rendimiento de las cooperativas de crédito individuales, auxiliando a sus directivos a encontrar soluciones para las deficiencias de estas instituciones. En este estudio, se clasificó como insolvente la cooperativa que: dejó de enviar estados financieros al Banco Central de Brasil, tenía un patrimonio neto negativo o patrimonio neto corregido negativo, o también si fue catalogada en las siguientes situaciones por el Banco Central de Brasil: paralizada, en liquidación extrajudicial, cancelada/cerrada y liquidación ordinaria. Utilizando una base de datos de 9.456 observaciones, recolectadas en una muestra de II2 cooperativas afiliadas a Sicoob-Crediminas entre enero de I995 y mayo de 2008 , se estimaron modelos de clase Logit. Los resultados obtenidos con el mejor ajuste permiten inferir que los indicadores "cartera de préstamos en mora/cartera total de préstamos", "capital institucional total/activo total", "activos no productivos/activo total" y "rendimientos de prestación de servicios/gastos administrativos", fueron los más relevantes en la determinación de la probabilidad de insolvencia de las cooperativas en la muestra. Estos resultados apoyan la hipótesis de que el seguimiento de los indicadores de contabilidad financiera del sistema Pearls, que no ha sido foco del análisis tradicional de estados financieros, es importante para determinar la probabilidad de insolvencia de cooperativas de crédito, al ayudar a sus gerentes a identificar factores de riesgo, así como en la creación de un punto de referencia para comparar el desempeño de las cooperativas, facilitando el proceso de supervisión de los reguladores. Sin embargo, la extrapolación de los actuales resultados para períodos posteriores y otras cooperativas de crédito en Brasil debe hacerse con cuidado, especificaciones alternativas deben ser evaluadas con el fin de captar los cambios en la coyuntura económica y estructura administrativa de las cooperativas, que pueden influir en los indicadores contables e financieros de las mismas. 


\section{PALABRAS CLAVE}

Insolvencia; Indicadores financieros de contabilidad; Uniones de credito; Sistema Pearls; Logit.

\section{REFERÊNCIAS}

ALTMAN, E. I. Financial ratios, discriminant analysis and the prediction of corporation bankruptcy. Journal of Finance, Berkley, v. 23, n. 4, p. 589-609, Sept. I968.

ALTMAN, E. I.; HALDEMAN, R. G.; NARAYANAN, P. Zeta analysis: a new model to identify bankruptcy risk of corporations. Journal of banking and finance, Amsterdam, v. I, n. I, p. 29-5I, Mar. I977.

AMERICAN ACCOUNTING ASSOCIATION. Accounting and reporting standards for corporate financial statements \& preceding statements \& supplements. Sarasota: AAA, I975. 64 p.

ASSAF NETO, A. Estrutura e análise de balanços: um enfoque econômico-financeiro. São Paulo: Atlas, I98I.

ATAY, G. Promoting international cooperation in resolving bank failures. Journal of Banking Regulation, Hampshire, v. 8, n. I, p. 66-72, Oct. 2006.

BEAVER, W. H. Financial ratios as predictors of failure. Journal of Accounting Research (Empirical Research in Accounting: Selected Studies), Chicago, v. 4, p. 7I-73, I966.

BLISS, R. R.; KAUFMAN, G. G. A comparison of U. S. corporate and bank insolvency resolution. Economic Perspectives, Federal Reserve Bank of Chicago, Chicago, v. 2Q, p. 44-56, May 2006.

BRAGA, M. J. et al. Investigating the solvency of Brazilian credit unions using a proportional Hazard model. Annals of Public and Cooperative Economics, Liege, v. 77, n. I, p. 83-106, Mar. 2006.

BRESSAN, V. G. F. Análise de insolvência das cooperativas de crédito rural do Estado de Minas Gerais. 2002. I23 f. Dissertação (Mestrado em Economia Aplicada)-Universidade Federal de Viçosa, Viçosa, 2002.

Seguro depósito e moral Hazard nas cooperativas de crédito brasileiras. 2009. 37I f. Tese (Doutorado em Economia Aplicada)-Universidade Federal de Viçosa, Viçosa, 2009.

BRESSAN, V. G. F.; BRAGA, M. J.; LIMA, J. E. de. Análise de insolvência das cooperativas de crédito rural do estado de Minas Gerais. Estudos Econômicos, São Paulo, v. 34, n. 3, p. 553-585, set. 2004. BROWN, C. O.; DINÇ, I. S. The politics of bank failures: evidence from emerging markets. The Quartely Journal of Economics, Cambridge, v. I20, n. 4, p. I4I3-I444, Nov. 2005.

CAMPBELL, A. Bank insolvency and the interests of creditors. Journal of Banking Regulation, Hampshire, v. 7, n. I-2, p. I33-I44, Mar. 2006.

Bank insolvency and the problem of nonperforming loans. Journal of Banking Regulation, Hampshire, v. 9, n. I, p. 25-45, Nov. 2007.

CARLSON, M. Are branch banks better survivors? Evidence from the depression era. Economic Inquiry, Malden, v. 42, n. I, p. III-I26, Jan. 2004.

COLE, R. A.; GUNTHER, J. W. Separating the likelihood and timing of bank failure. Journal of Banking and Finance, Amsterdam, v. I9, n. 6, p. 1073-1089, Sept. 1995. 
CORRÊA, A. C. C.; COSTA, R. D. de M.; MATIAS, A. B. Previsão de insolvência de pequenos bancos brasileiros. In: SEMINÁRIOS EM ADMINISTRAÇÃO, 9., 2006, São Paulo. Anais... Disponível em: <http://www.cepefin.org.br/publicados_pdf/semead_peq_bancos.pdf>. Acesso em: I3 mar. 2009.

DEYOUNG, R. The failure of new entrants in commercial banking markets: a split-population duration analysis. Review of Financial Economics, New Orleans, v. I2, n. I, p. 7-33, Mar. 2003.

GIMENES, K. M. I. Análise do comportamento dos administradores financeiros com respeito ao custo e estrutura de capital aplicado as cooperativas agropecuárias do Estado do Paraná. I998. 338 f. Tese (Doutorado em Administração de Empresas)-Universidade de León, Espanha, I998.

GREENE, W. H. Econometric analysis. New Jersey: Prentice Hall, 2003.

HAYASHI, F. Econometrics. New Jersey: Princeton University Press, 2000.

HEIJ, C. et al. Econometric methods with applications in business and economics. New York: Oxford University Press, 2004.

HENDRIKSEN, E. S.; BREDA, M. F. van. Teoria da contabilidade. 5. ed. São Paulo: Atlas, I999.

IMAI, M. Political influence and declarations of bank insolvency in Japan. Journal of Money, Credit and Banking, Columbus, v. 4I, n. I, p. I3I-I58, Feb. 2009.

JANOT, M. M. Modelos de previsão de insolvência bancária no Brasil: aplicação de diferentes modelos entre I995 e I998. I999. 94 f. Dissertação (Mestrado em Economia)-Pontifícia Universidade Católica do Rio de Janeiro, Rio de Janeiro, I999.

KANITZ, S. C. Como prever falências. São Paulo: McGraw-Hill, I978.

LANE, W. R.; LOONEY, S. W.; WANSLEY, J. W. An application of the Cox Proportional Hazards Model to Bank Failure. Journal of Banking and Finance, Amsterdam, v. IO, n. 4, p. 5II-53I, Dec. I986.

LASTRA, R. M. Northern Rock, UK bank insolvency and cross-border bank insolvency. Journal of Banking Regulation, Hampshire, v. 9, n. 3, p. I65-I86, May 2008.

MÁRIO, P. do C.; AQUINO, A. C. B. de. Falências. In: IUDÍCIBUS, S. de; LOPES, A. B. Teoria avançada da contabilidade. São Paulo: Atlas, 2004. p. 186-232.

MARTINS, M. S. A previsão de insolvência pelo modelo de Cox: uma contribuição para a análise de companhias abertas brasileiras. 2003. IO2 f. Dissertação (Mestrado em Administração)-Escola de Administração, Universidade Federal do Rio Grande do Sul, Porto Alegre, 2003.

MATIAS, A. B.; SIQUEIRA, J. O. Risco bancário: modelo de previsão de insolvência de bancos no Brasil. Revista de Administração, São Paulo, v. 3I, n. 2, p. 19-28, abr./jun. I996.

MAYES, D. G. Who pays for bank insolvency? Journal of International Money and Finance, New York, v. 23, n. 3, p. 515-55I, Apr. 2004.

Who pays for bank insolvency in transition and emerging economies? Journal of Banking and Finance, Amsterdam, v. 29, n. I, p. I6I-I8I, Jan. 2005.

MODÉ, L. Medida pode não destravar o crédito. O Estado de S. Paulo, São Paulo, 27 mar. 2009. Caderno B, p. B3.

MUÑOZ, J. Calidad de cartera del sistema bancario y el ciclo económico: una aproximación econométrica para el caso peruano. 200I. Disponível em: <http://www.bcrp.gob.pe/docs/Publicaciones/ Revista-Estudios-Economicos/04/Estudios-Economicos-4-5.pdf>. Acesso em: Io maio 200 I. OHLSON, J. A. Financial ratios and the probabilistic prediction of bankruptcy. Journal of Accounting Research, Chicago, v. I8, n. I, p. I09-I3I, Spring I980. 
- RAM, REV. ADM. MACKENZIE, V. 12, N. $2 \bullet$

OTTA, L. A. Bancos terão reforço de R \$ 50 bilhões. O Estado de S. Paulo, São Paulo, 27 mar. 2009. Caderno B, p. Bi.

PAGNUSSATT, A. Guia do cooperativismo de crédito: organização, governança e políticas corporativas. Porto Alegre: Sagra Luzzatto, 2004.

RIBEIRO, D. M. Insolvência de cooperativas de crédito: uma aplicação do modelo de Cox com covariáveis dependentes do tempo. 2008. 94 f. Trabalho de Conclusão de Curso (Especialização em Estatística)-Instituto de Ciências Exatas, Universidade Federal de Minas Gerais, Belo Horizonte, 2008.

RICHARDSON, D. C. Pearls monitoring system. World Council of Credit Unions, Oct. 2002. (Toolkit series, n. 4). Disponível em: <http://www.coopdevelopmentcenter.coop/publications/ WOCCU\%2oFiles/pearlsvol4.pdf>. Acesso em: 28 maio 2008.

ROCHA, F. Previsão de falência bancária: um modelo de risco proporcional. Pesquisa e Planejamento Econômico, Rio de Janeiro, v. 29, n. I, p. I37-I52, abr. I999.

SILVA, J. P. Administração de crédito e previsão de insolvência. São Paulo: Atlas, I983. Análise e decisão de crédito. São Paulo: Atlas, I988.

SOARES, M. M.; MELO SOBRINHO, A. D. de. Microfinanças: o papel do Banco Central do Brasil e a importância do cooperativismo de crédito. Brasília: BCB, 2007.

STATACORP. Stata Statistical Software: realease Io: reference I-P. College Station, TX: StataCorp LP. 2007.

TZIRULNIK, L. Intervenção e liquidação extrajudicial das instituições financeiras. 3. ed. São Paulo: Revista dos Tribunais, I997.

VASCONCELOS, R. W. B. de. Identificação de indicadores econômico-financeiros para análise de cooperativas de crédito, singulares ou centrais. Belo Horizonte: Departamento de Supervisão Indireta e Gestão da Informação (Desig), Banco Central do Brasil, 2006.

VERBEEK, M. A guide to modern econometrics. 2. ed. Chichester: John Wiley \& Sons, 2004. WATTS, R. L.; ZIMMERMAN, J. L. Positive accounting theory. Englewood Cliffs: Prentice Hall, I986.

WHEELOCK, D.; WILSON, P. W. Productivity changes in U.S. Banking: I984-93. Federal Reserve Bank of St. Louis, I994. 30 p. Working paper: 94/O2IA. 